\title{
Why Consider the Clients Partner in Psychotherapy?
}

\author{
Jon Hay and Stephen Appel
}

\author{
Auckland City Therapy, ANd AUT University, AUCKLAND
}

\begin{abstract}
The bi-directional impacts of an individual's psychotherapy on their partner and of the partner and their relationship on the therapy should be a consideration throughout treatment. There is a bias in the literature towards either an individual or a couples approach to therapy, but only scattered mention of working with a blend of the two. This article considers how, during the process of change in individual therapy, new problems might arise in a client's romantic relationship. Furthermore, the client's significant other might resist or otherwise hamper their partner's therapy if they do not accept or understand the changes that are taking place. Finally, some ethical arguments are raised which add to the case that psychotherapists should not ignore the impact that psychotherapy has on their client's relationships and vice versa.
\end{abstract}

\section{Whakarāpopoto}

Ko ngā awe o te arongarua o te whakaoranga hinengaro tautahi ki tōna hoa me te hoa tau atu hoki ki tā rāua tirohanga ki te whaihauora e tika ana kia āta whakaarohia huri noa o te rongoā. E whakawhirinaki ana ngā tuhinga ki te takitahi ki tā te tokorua kauawhi ki te rongoā, engari torutoru noa iho te whakahuanga ake o te whakamahitanga i te hononga o ēnei. E titiro ana tēnei tuhinga i te wā o te huringa o te haumanu takitahi, tērā pea ka ara ake he raruraru hou ki te noho whaiāipo a te kiritaki. I tua atu hoki, tērā pea ka ātete atu tērā o te kiritaki ka whakaroa rānei i te whakaoranga o tana hoa mena kāre e whakaae e moohio rānei ki ngā huringa hou. I te mutunga, ka whakaarahia ake ètahi whakapae matatika e tautoko ana i te kōrero kia kaua te kaiwhakaora hinengaro e noho turi ki te awe o te whakaoranga hinengaro ki ngā hononga o ā rātou kiritaki, ā, huri whakamuri hoki.

Keywords: marital therapy; marriage therapy; couples therapy; psychotherapy partner; combining individual couple therapy.

"Every cobbler thinks leather is the only thing." (Mills, 2000, p.19)

Hay, J., \& Appel, S. (2013). Why consider the client's partner in psychotherapy? Ata: Journal of Psychotherapy Aotearoa New Zealand, 17(1), 55-64. DOI: 10.9791/ajpanz.2013.04 @ New Zealand Association of

Psychotherapists Inc. 
Individual psychotherapists very often find that their client's significant other is "in" the therapy. It may be that, like Banquo's ghost, the partner is an invisible presence, and prominent in the dynamic. It might be that the partner is absent from the work to the extent that the therapist may wonder why he or she is missing. If the therapist is principally an individual therapist by training or by preference then such matters could be brushed aside without due consideration. In this article we suggest that, if a client is in a relationship, then that relationship will have an impact on the therapy and vice versa. Indeed, to some degree or other, individual therapy is also couples therapy. Thus, we argue that individual therapists should consider including the partner in the work in some way.

\section{A Dichotomy in the Literature}

There is a dichotomy in the psychodynamic literature: that psychotherapy involves either an individual or a couple therapy approach to treatment, one or the other. Whilst some couple therapy writers give occasional note to the usefulness of individual sessions within the couple therapy format (e.g., Johnson, 2004; Scharff \& Scharff, 1997) any mention given is usually brief. However, that amount is generous when compared to the scarcity with which individual therapists mention meeting the couple. In this article we bring together the ideas of writers who have considered this matter.

Whilst many psychotherapists lean towards the classical approach which involves only meeting with and treating the individual, Phillips (1983) warned that focusing on an exclusively individual format overlooks the important point that "any form of therapy is an intervention in a system of interpersonal relationships" (p.11). When an individual is having psychotherapy their treatment affects their significant other, regardless of whether the therapist thinks this way or not. Heitler (2001) suggested that focusing exclusively on the individual is overly simplistic and is likely inadvertently to harm some patients. She said: "Emotional health is based on the complex paradoxical reality that people need both individual happiness and relationship success. Oversimplification of treatment to address just one dimension risks harming the other" (p.380).

Whilst many psychotherapists work with both individuals and couples, a widespread view is that they must decide to treat only one partner or only the couple (Weeks \& Treat, 2001). This dualism has little impact when the client's needs are straightforward, for example, individual therapy to help long-standing depression, or couple therapy to help with relationship conflict.

However, as we show, sometimes effective treatment may warrant a shift from one format to the other or a combination of both; an either/or approach may not be the best fit. For example, what happens when a client requests individual psychotherapy that seems fitting initially, but, as their problem unfolds, their partner figures prominently in their struggle; or, when individual therapy is underway but, as the treatment progresses, change in the client impacts problematically on their partner?

\section{The Bias Towards Individual Therapy}

Psychodynamic therapists commonly assume that for deep change to occur, individual 
therapy is the only context that really facilitates this. Whilst this may sometimes be true, others argue that couple therapy can enable change which cannot be achieved in individual work; as Burch and Jenkins (1999) put it: "The often fierce and fast-paced interactional field of [couple] therapy is rich in occasions of intimate encounters, providing certain opportunities lacking in individual psychotherapy" (p. 243).

Psychotherapists who prefer not to work with couples or who are not trained in couple therapy may have a bias towards individual psychotherapy, making them more likely to assume individual therapy as the default and fail to consider whether alternative treatment formats could be more helpful (Zeitner, 2003). Hurvitz (1967) described how this bias, if unacknowledged, might manifest itself in practice; he depicted a common scenario in which the individual therapist alludes to the fact that, in order to obtain greater psychological well-being, a subsequent disturbance in the client's relationships may be either a necessary sacrifice, or simply a reconciliation with the truth.

Another widespread notion voiced by Zeitner (2003) is that any characterological or interpersonal problems experienced by the client will inevitably manifest themselves within the individual therapy, either by disclosure or through observance of the transference. This view, he argued, fails to consider the importance of the intersubjective aspect of all human relationships.

Kottler and Carlson (2003) stressed the importance of having a sense of flexibility and a pluralistic approach to psychotherapy, rather than simply relying on a rigid format. They said that a failure in therapy happens when the therapist reaches the limit of one model and then is unable to reach for another.

The following two sections will look at some common scenarios which may warrant consideration for change in the therapy format. The first of these is when personal changes in individual therapy lead to problems in the client's relationship with their partner.

\section{Individual Therapy that Leads to new Problems in the Couple Relationship}

Graziano and Fink (1973) and Coyne (1976) noted how individual therapy impacts on the client's psychosocial environment, often placing unwanted changes and demands on significant others. This runs the risk of producing new conflicts or aggravating and compounding old difficulties. Whilst the common assumption is that individual psychotherapy is for the benefit of all, there is frequent mention in the literature around the potential of a negative impact resulting from changes which are unwelcome by the patient's partner (e.g., Colson, Lewis, \& Horwitz, 1985; Kohl, 1962; Moran, 1954; Zeitner, 2003).

Observations of this type are nothing new. Freud (1920/1956) noted the frequency in which he encountered his female clients suffering marital difficulties subsequent to their treatment:

[I]t constantly happens that a husband instructs the physician as follows: "My wife suffers from nerves, and for that reason gets on badly with me; please cure her, so 
that we may lead a happy married life again.” But often enough it turns out that such a request is impossible to fulfil - that is to say, the physician cannot bring about the result for which the husband sought the treatment. As soon as the wife is freed from her neurotic inhibitions she sets about getting a separation, for her neurosis was the sole condition under which the marriage could be maintained. (p.150)

However, whilst many therapists describe their own observations of new problems arising following individual therapy, researchers have reported mixed findings. For example, Pomerantz and Seely (2000) conducted a study in which they asked 473 undergraduates to envision their partner as having individual psychotherapy and then answered questions describing their distress to specific scenarios. Overall the study found that participants felt some distress at simply imagining having a partner in therapy, with the most distressing responses occurring when clients refused to discuss their therapy, and when partners were unaware of the reason for their partner's therapy. Similarly, Gurman and Kniskern (1978) carried out a meta-analysis in which they analysed over 200 reports and studies that examined relationship deterioration during family or marital therapy. They found that negative therapeutic effects were twice as likely when the patient was seen in individual therapy as distinct from a format that included both partners.

On the other hand, Hunsley and Lee (1995) conducted a meta-study of 20 independent clinical samples which looked at the impact that individual therapy had on relationships and concluded that there were fewer negative consequences than some early studies had indicated. They suggested that perhaps the increased number of female therapists contributes to this decrease in partner difficulties. In the past, clients of therapy have often been female and therapists were usually male, a situation/dynamic which was likely to have invited inadvertent negative comparisons between the nurturing therapeutic relationship and troubles at home. Hunsley and Lee argued that treatment with a samesex therapist can reduce this risk. They also suggested that contemporary therapists may be more likely to encourage their clients to explore what they can do towards improving their happiness at home rather than simply complaining about their spouse. Hunsley and Lee concluded that, whilst individual therapy often causes disruption to the relationship, this disturbance is usually temporary and there is no conclusive evidence to the long-term negative impact on the patient's relationship.

However, a critique of Hunsley and Lee's findings is that psychotherapists cannot reliably predict whether a therapy will be long-term. Therefore, even though Hunsley and Lee concluded that disruption is often temporary, if the therapist does not attend to the partner in some way, they will be left to make a judgment call on whether or not the client will remain in therapy long enough, or whether the client's relationship is strong enough to withstand any problems that may have developed during the course of the treatment.

Nevertheless, we must not overlook the fact that clients' partners are often pleased with the outcome of their spouses' individual treatment and they commonly find that it benefits themselves as well as their relationship (Lefebvre \& Hunsley,1994). Thus, holding 
in mind that individual treatment aims to be advantageous, Hunsley and Lee (1995) suggested that, when working with clients with partners, therapists discuss both the positive and negative impacts that individual treatment may have on their relationship and, in doing so, make it clear to the client the options of both individual and couple treatment.

In short, any therapy that has an impact on an individual will subsequently have an impact on their partner. As Garfield (2004) pointed out: "problems may occur in individual therapy when the therapist is unaware of the impact of the therapeutic alliance on the patient's relationships outside therapy" (p. 460). Therefore, if the individual therapist recognises that they have activated a disturbance in the client's relationship with their partner, this is the time for the therapist to encourage a consultation for couple therapy.

\section{Resistance or Sabotage by the Partner}

Both Mittelmann (1944) and Pollak (1965) pointed out that consideration should be given to the client's spouse, stating that change in one spouse is not always appreciated by the other. When the therapist does not give appropriate attention to the spouse's role in the client's difficulties, Hurvitz (1967) suggested that the spouse may be resistant to any change that the client attempts to bring about. If the partner does not welcome the changes in their previously familiar environment, it is possible that they may sabotage the therapy in conscious or unconscious ways.

A common opinion amongst individual therapists, according to Brody (1961), is that "in prolonged treatment with one individual, the idea has been expressed that if one member, the presumed 'sicker one' got 'straightened out', the family difficulties would be automatically cleared up" (p. 98). This idea is unrealistic, he explained, because the real problem is still being ignored. He went on to say that "the untreated partner may be treatment-rejecting precisely because he is afflicted with an even more severe disturbance than the treatment-accepting partner" (ibid.,p. 98 ). In other words, the client who arrives at the therapist's office for treatment may not be the only one with a problem, and if treated in isolation, the other's problems, as well as the impact of individual treatment of the partner, are being overlooked.

Kohl (1962) conducted a ten year study in which he observed marital partners who were not included in the therapy exhibiting various types of reaction to their partners' improvement: these ranged from resentment or suspicion of the therapist or the therapy, recurrence of addictive behaviours such as alcoholism, through threats of divorce, to threats or attempts of suicide. Ackerman (1958) also described commonly observing one partner improving as the other got worse, or one partner maturing as the other becomes more depressed.

These pathological reactions are, however, often predictable, and thus, in such circumstances, as Kohl (1962) observed, then the marital partner should be included in the therapy as early as possible. Kohl also suggested that the therapist's ability to manage the conscious and unconscious hostility of the partner effectively has a direct impact on the success or failure of the patient's treatment. If and when to consider including the 
partner in the therapy is, of course, a judgement call. Zeitner (2003) described a common scenario when, after spending time in individual therapy and making significant changes, the client complains to the therapist that their spouse

is still reacting to him or her as if he were controlling, helpless, stubborn, or whatever other characteristic might have been the focus of struggle. It is often at this point that the [therapist] and sometimes the patient, too, become aware of the presence of interlocking pathology which will less likely improve without couple therapy. (p.350)

Likewise, Carveth and Hartman (2002) commented that, when the patient has been in individual therapy for some time and begins to notice that their partner not only is not changing with them, but is actually sabotaging any healthy progress, it may be time for the therapist to consider including the partner in the treatment. Kohl (1962) noted that inclusion of the partner is indicated when they react to the patient's obvious progress either by a resistance to their partner's improvement, or by the development of clinical illness. He says that, in these cases, it is often clear that the well-being of one partner has a direct relation to the illness of the other. Again, it may be that the partner who seeks treatment may not be the sicker one, and this may be one of the reasons that partners react badly to improvement in the other (Berger \& Berger, 1979).

\section{Ethical Reasons for Considering the Partner}

In addition to the practical considerations discussed so far, there are also ethical reasons for considering the partner. Sider and Clements (1982) noted that what is good for the individual may not always be good for the couple and suggested that individual therapists tend to overlook the ethics of considering the partner and, indeed, avoid it in a variety of ways. For example, the individual therapist might maintain that there is no conflict between their therapeutic loyalty to the good of the individual and the good of the relationship of which they are a part. The assumption is that the good of one, in the long run, works for the good of the other. Another common oversight is that the therapist's sole interest is in achieving the goals of the therapy which have been defined by the participants of the therapy, that is, the therapist is simply an agent of the process and has no interest in the outcome.

During the initial assessment for individual therapy, many therapists will routinely communicate to the client their qualifications, perhaps discuss the procedure and goals of therapy, and maybe establish a therapeutic contract of sorts. However, fully informing the client of the possible side-effects of therapy is often glanced over during this initial interview (Hare-Mustin, Marecek, Kaplan, \& Liss-Levinson, 1979). What is being overlooked is that clients often enter into therapy believing that the process will enhance their relationship with their partner and, whilst this may often be true, as mentioned previously, there is the possibility that therapy may well harm it (Hurvitz, 1967).

Indeed, Heitler (2001) posed the question: "Is it ethical to offer married individuals assessment and treatment that does not include the spouse?” (p. 349) Her rationale is 
that, if therapy is started with one individual and not their partner, it introduces the likelihood that the asymmetrical alliance between the therapist and the spouse will jeopardise the therapist's ability to work with both partners later if the need arises. Likewise, Lefebvre and Hunsley (1994) suggested that partners of clients in therapy should be included in discussion about the possible impact therapy can have on a relationship, and that both partners are made aware that any impact to their relationship could be positive or negative.

Phillips (1983) said that, in order to practice ethically, therapists need to develop and hold a clear premise of what constitutes appropriate concern for their clients' overall wellbeing, and, if necessary, they should broaden this view so that it includes the patient's wider socio-psychological environment and not simply be confined to resolving unconscious conflict in the individual: "realistic expectations of the potential benefits and costs of entering treatment should be fostered from the beginning, and include sufficient information regarding possible, albeit unintended, negative side-effects” (p.10).

Whilst the views expressed so far have all leant towards an ethical obligation to inform the client of the potential outcomes of therapy at the onset, it is true that real life practicalities may not always make this possible, for example, if the client presents in crisis. However, whilst the practicalities of attending to the client's immediate concerns may make these explanations unwelcome or even unhelpful, Phillips (1983) maintained that "therapists must accept the ethical obligation to continually examine the effects of their interventions on the lives of the clients they serve" (p. 12). Therefore, if practical matters make the timing of this conversation inappropriate, then, once the crisis is over, the ethical conversation should be initiated by the therapist if the client intends to continue therapy. Phillips stated that: "just as the physician is obligated to inform the patient of the possible side-effects of a particular drug, and the lawyer is obligated to provide information regarding the possible gains and losses involved in legal action, the psychotherapist incurs a similar responsibility" (p. 10).

On a final note we must be mindful that including the partner in a conjoint format may at times be damaging. The obvious example is when abuse or violence is present in the relationship and expression of vulnerability in the therapy session may have detrimental implications outside of therapy. In situations such as this it may be better to refer the abusive partner to a separate therapy. The point being made here is that the partner is still considered in the therapy, and the therapist must make a judgement call as to the most appropriate format for their treatment.

\section{A Brief Theoretical Interlude}

The matter considered in this article requires peculiar mental contortions by the therapist. Indeed, it could be said that what is required defies rationality. Saying that Jill is an individual and in relationship with James confounds at least the second of the three the laws of scholastic thought: identity, non contradiction, and the law of the excluded middle. According to Aristotle "A is B" and "A is not B" are mutually exclusive and thus illogical, statements. However, in our case it does seem as though we both say and mean that "Jill is an individual" and "Jill is not an individual". 
Existentially Jill is an individual.Jill has the freedom to act and must take responsibility for those actions, that is, not to implicate others. She is existentially alone and she will die (alone). Most therapists would accept some version of this.

However, Jill is not an individual in the Winnicottian sense of there being no such thing as a baby, only a nursing couple. In this view - again, one widely accepted by psychotherapists - a person exists only in relation to other people.

The problem of individual and couples therapy requires, we suggest, that the therapist be able to understand, believe, and act according to the opposed ideas that Jill is singular and alone as well as being "at one with" her husband in some non reducible way.

Not only is this a practical problem (how is one to keep both realities simultaneously in one's mind?), it is a theoretical problem (how is one to think about incompatible matters?). Come to think about it, the individual/not individual contradiction is but one of many incommensurable ideas in psychotherapy: something can be both conscious and unconscious; an adult has a child within him/her; one can love and hate someone; transference (the past being active in the present); and so on.

We end this interlude by reminding the reader of Freud's dream theory. To the awake mind, dreams are irrational but, said Freud, dreams operate according to the laws of dream logic, in particular: displacement (one thing standing for another), and condensation (one thing containing or entailing another). It seems to us that the richness of these ideas has not yet been fully extracted.

\section{Summary}

This article has discussed how psychodynamic literature commonly focuses on either individual or couple therapy with little written regarding transitioning or combining the two. This dichotomy flows into clinical practice, leaving many therapists feeling as if they need to choose one format or the other. An individual therapy bias has been suggested and discussion given to understanding how this bias could be harmful to the client if not recognised. If the limits of individual therapy are overlooked by the clinician then an individual format may be chosen as default, even when it might not be the best course of action. If indiscriminately applied without consideration of the client's relationship, individual therapy runs the risk of the spouse being resistant to any change made in their partner and the possibility of new problems arising. This would then force the therapist to decide either to include the partner in the therapy in some way or trust that these problems will be attended to appropriately in due course within the context of the individual therapy. Finally, ethical arguments have been raised that suggest an obligation to the therapist to attend to the client's relationship appropriately and also to fully inform the client at the onset of therapy that their treatment may have an impact on their relationship.

\section{References}

Ackerman, N. W. (1958). The psychodynamics of family life. New York, NY: Basic Books. Berger, M. M., \& Berger, L. F. (1979). Couple therapy by a married couple. Journal of the 
American Academy of Psychoanalysis, 7(2), 219-240.

Brody, S. (1961). Simultaneous psychotherapy of married couples: Preliminary observations. Psychoanalytic Review, 48(4), 94-107.

Burch, B., \& Jenkins, C. (1999). The interactive potential between individual therapy and couple therapy: An intersubjective paradigm. Contemporary Psychoanalysis, 35(2), 229-252.

Carveth, D., \& Hantman, J. (2002). Transcending the dangers of the dyad: Enhancing therapeutic triangulation by working individually with patients in relationships. Modern Psychoanalysis, 27(1), 31-49.

Colson, D., Lewis, L., \& Horwitz, L. (1985). Negative outcome in psychotherapy and psychoanalysis. In D. Mays \& C. Franks (Eds.), Negative outcome in psychotherapy and what to do about it (pp. 59-75). New York, NY: Springer.

Coyne, J. C. (1976). The place of informed consent in ethical dilemmas. Journal of Consulting and Clinical Psychology, 44(6),1015-1016. DOI:10.1037/0022-006X.44.6.1015

Freud, S. (1956). The psychogenesis of a case of homosexuality in a woman. In The standard edition of the complete psychological works of Sigmund Freud. (Vol.18, pp.145-172; J. Strachey, Ed. and Trans.). London, UK: Hogarth Press. (Original work published 1920)

Garfield, R. (2004). The therapeutic alliance in couples therapy: Clinical considerations. Family Process, 43(4), 457-465. DOI:10.1111/j.1545-5300.2004.00034.x

Graziano, A. M., \& Fink, R. S. (1973). Second-order effects in mental health treatment. Journal of Consulting and Clinical Psychology, 40(3),356-364. DOI:10.1037/hoo34549

Gurman, A. S., \& Kniskern, D. P. (1978). Deterioration in marital and family therapy: Empirical, clinical, and conceptual issues. Family Process, 17(1), 3-20.

DOI:10.1111/j.1545-5300.1978.00003.x

Hare-Mustin, R. T., Marecek, J., Kaplan, A. G., \& Liss-Levinson, N. (1979). Rights of clients, responsibilities of therapists. American Psychologist, 34(1), 3-16. DOI:10.1037/0003066X.34.1.3

Heitler, S. (2001). Combined individual/marital therapy: A conflict resolution framework and ethical considerations. Journal of Psychotherapy Integration, 11(3), 349-383.

DOI:10.1023/A:1016606317558

Hunsley, J., \& Lee, C. M. (1995). The marital effects of individually-oriented psychotherapy: Is there evidence for the deterioration hypothesis? Clinical Psychology Review, 15(1), 1-22. DOI:10.1016/0272-7358(94)00038-7

Hurvitz, N. (1967). Marital problems following psychotherapy with one spouse. Journal of Consulting Psychology, 31(1), 38-47. DOI:10.1037/hoo24228

Johnson, S. (2004). The practice of emotionally-focused couple therapy ( $2^{\text {nd }}$ Ed.). New York, NY: Brunner-Routledge.

Kohl, R. N. (1962). Pathologic reactions of marital partners to improvement of patients. American Journal of Psychiatry, $118(11), 1036$-1041. DOI:10.1176/appi.ajp.118.11.1036

Kottler, J. A., \& Carlson, J. (2003). Bad therapy: Master therapists share their worst failures. New York, NY: Routledge.

Lefebvre, M., \& Hunsley, J. (1994). Couples' accounts of the effects of individual psychotherapy. Psychotherapy: Theory, Research, Practice, Training, 31(1), 183-189. DOI:10.1037/0033-3204.31.1.183

Mills, C.W. (2000). The sociological imagination. New York, NY: Oxford University Press. 
Mittelmann, B. (1944). Complementary neurotic reactions in intimate relationships. Psychoanalytic Quarterly, 13, 479-491.

Moran, M. L. (1954). Some emotional responses of patients' husbands to the psychotherapeutic course as indicated in interviews with the psychiatric caseworker. American Journal of Orthopsychiatry, 24(2), 317-325. DOI:10.1111/j.1939-0025.1954.tbo2021.x

Phillips, J. B. (1983). Some ethical concerns regarding the individual psychotherapy of the married client. Canadian Psychology/Psychologie Canadienne, 24(1), 8-13. DOI:10.1037/ hoo80686

Pollak, O. (1965). Sociological and psychoanalytic concepts in family diagnosis. In B. L. Greene (Ed.), The psychotherapies of marital disharmony. New York, NY: Free Press.

Pomerantz, A. M., \& Seely, E. A. (2000). Under what conditions is individual psychotherapy distressing to clients' romantic partners? An empirical analogue study. Journal of Contemporary Psychotherapy, 30(3), 255-260. DOI:10.1023/A:1004190615611

Scharff, D. E., \& Scharff, J. S. (1997). Object relations couple therapy. London, UK: Jason Aronson.

Sider, R. C., \& Clements, C. (1982). Family or individual therapy: The ethics of modality choice. American Journal of Psychiatry, 139(11), 1455-1459.

Weeks, G., \& Treat, S. (2001). Couples in treatment: Techniques and approaches for effective practice. London, UK: Routledge.

Zeitner, R. M. (2003). Obstacles for the psychoanalyst in the practice of couple therapy. Psychoanalytic Psychology, 20(2), 348-362. DOI:10.1037/0736-9735.20.2.348

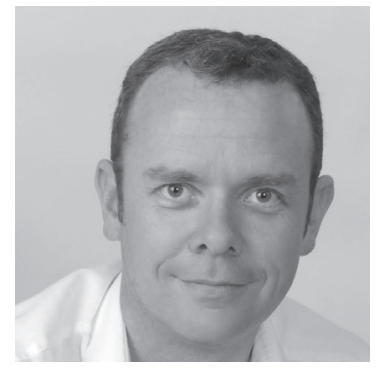

Stephen Appel, PhD, is a Senior Lecturer in the Department of Psychotherapy, AUT University. In his private practice at the Apollo Centre, Auckland, he sees individual adults and couples and supervises therapists and counsellors who do the same.Contact details: sappel@aut.ac.nz .
Jon Hay is a Counsellor and registered Psychotherapist. He works in private practice at Auckland City Therapy where he sees individual adults and couples. He has a keen interest in the overlap between individual and couple approaches to treatment. Contact details: jonhay.nz@gmail.com . 